\title{
THE HUMORAL RESPONSE TO AN ALLOGRAFT
}

\author{
I. V. HUTCHINSON, YASMIN ALAM and W. R. AYLIFFE \\ Manchester
}

\begin{abstract}
SUMMARY
Antibodies are known to damage grafted tissues by a variety of means, so it is important to know how the humoral response is initiated. In this paper we summarise the cellular events in $B$ cell activation, the mechanisms of antibody-mediated rejection and the evidence that antibody apparently does not contribute to early corneal graft rejection. The role of antibodies in chronic graft loss is discussed.
\end{abstract}

Grafted allogeneic tissues are usually vigorously attacked and destroyed in untreated recipients. ${ }^{1}$ The $\mathrm{CD}^{+} \mathrm{T}$ cell is central to this process since the cytokines it elaborates, such as interleukin (IL)-2, -4, -5 and -6 , interferon gamma (IFN $\gamma$ ) and tumour necrosis factor-beta (TNFß), drive different pathways of rejection (Fig. 1). The major mechanisms of graft destruction are specific T-cell-mediated cytotoxicity, antibody-mediated damage and inflammatory reactions.

The role of antibody in graft rejection has been debated for years. ${ }^{2}$ The purpose here is to review in general terms the requirements for B cell activation, to discuss the kinds of graft damage that could be brought about by antibodies, and to consider their contribution to corneal transplant rejection.

\section{IMMUNE RECOGNITION OF TRANSPLANTED TISSUES}

The activation of $B$ cells is dependent on $T$ cell help, so first we must consider the activation of $T$ lymphocytes. $\mathrm{T}$ cells of the recipient respond to major histocompatibility complex (MHC) molecules which contain a peptidic fragment in a groove on the membrane-distal surface of the molecule (Fig. 2). Hence, the $\mathrm{T}$ cell receptor contacts both the MHC molecule and the bound peptide.

The cytokine-producing $\mathrm{T}$ helper cells generally have the CD4 marker on their surface and recognise MHC class II molecules arrayed on the membrane of

Correspondence to: Professor I. V. Hutchinson, School of Biological Sciences, University of Manchester Medical School, Oxford Road, Manchester M13 9PT, UK. Fax: (061) 2755640. specialised antigen presenting cells (APC). These APC have the capacity to acquire and degrade foreign proteins and to present the resulting peptides as complexes with MHC class II molecules.

In the case of transplanted tissues which contain a powerful APC population, namely the interstitial

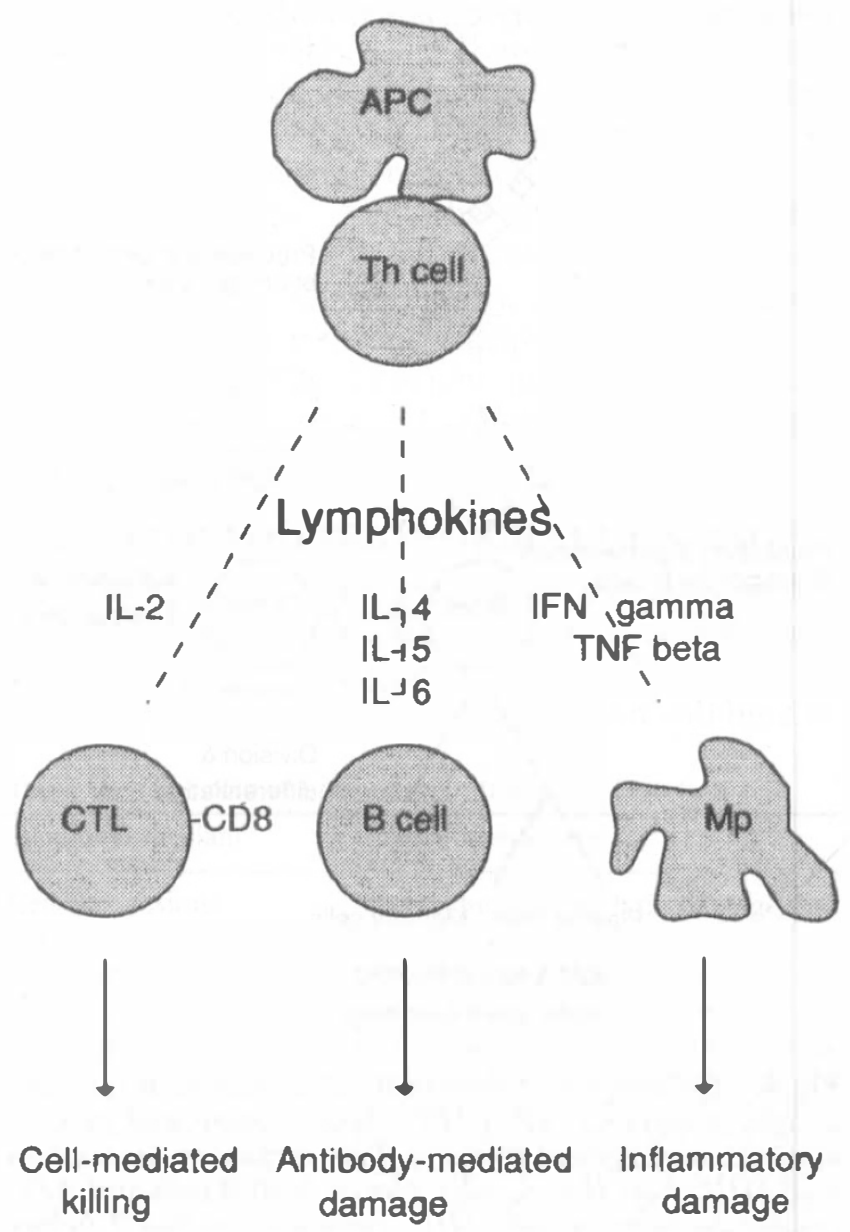

Fig. 1. The major pathways of graft rejection. APC, antigen presenting cell; Th, T helper lymphocyte; IL-2, interleukin-2 ( $T$ cell growth factor); $I L-4,-5$ and -6 , interleukins 4, 5 and 6 (B cell growth factor $I$ and $B$ cell differentiation factors $I$ and II); IFN, gamma interferon gamma; TNF beta, tumour necrosis factor beta or lymphotoxin; CTL, cytotoxic T lymphocyte (killer T cell); $B$, antibody-producing $B$ lymphocyte; $M p$, macrophage. 


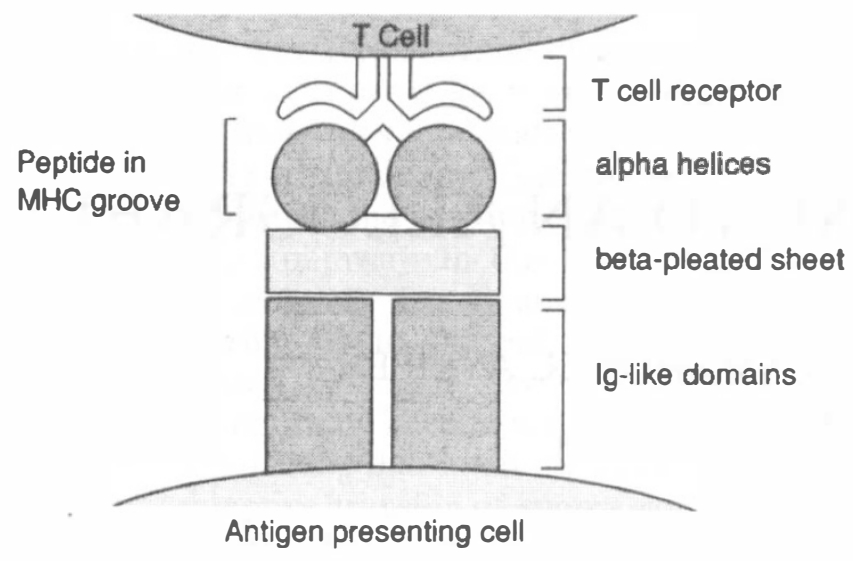

Fig. 2. The interaction between the $T$ cell receptor and MHC molecules. The alpha and beta chains of the $T$ cell receptor engage the flat surface comprised of the top surface of the alpha helices of an MHC molecule between which lies an oligopeptide. Peptides derived from proteins within the cell are associated with MHC class I molecules, while peptides derived from extracellular proteins are presented within the groove of MHC class II molecules.

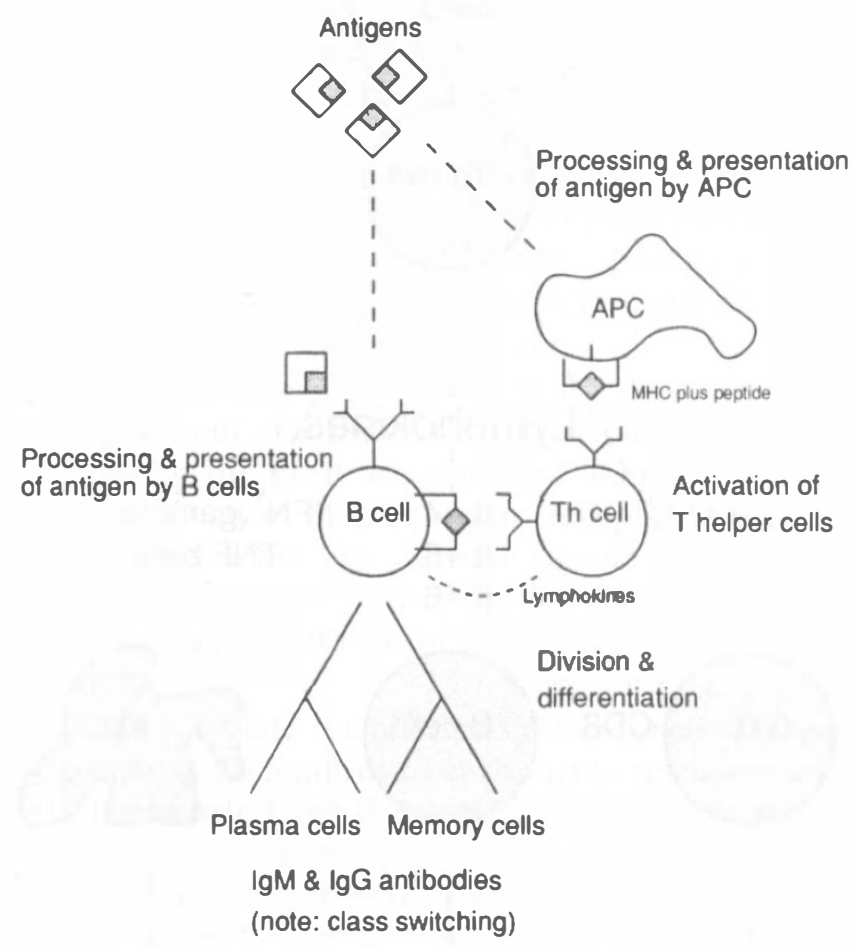

Fig. 4. Cellular interactions in $B$ cell activation. $B$ cells and antigen presenting cells (APC) both acquire and process antigens, and present them on their surface in association with MHC class II molecules. Hence, both B cells and APC present the same peptide-MHC complexes so that Thelper cells activated by the peptide-MHC on APC can interact directly with the same peptide-MHC on $B$ cells. The contact between $B$ and $T$ helper cells leads to the delivery of lymphokines (IL-2,IL-4, IL-5 and IL-6) to the B cell. These lymphokines drive the division and differentiation of $B$ cells into antibody-producing plasma cells and into memory $B$ cells. The switching of $B$ cells from the synthesis of $\operatorname{IgM}$ to $\operatorname{IgG}$ is also under the influence of lymphokines. These cellular events all take place in the central lymphoid tissues (lymph nodes and spleen).

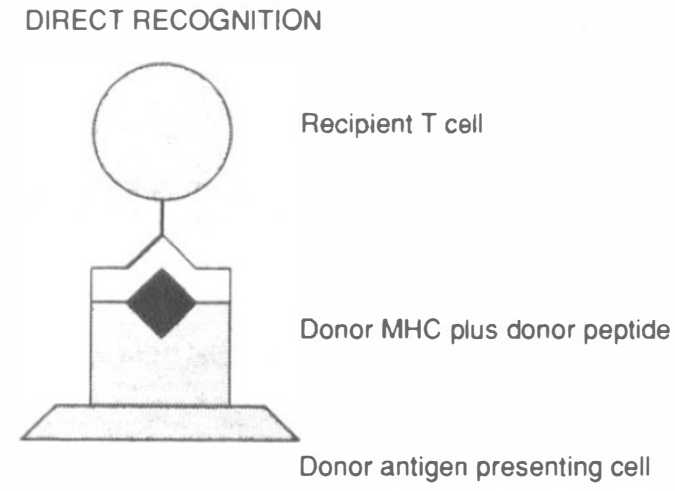

INDIRECT RECOGNITION

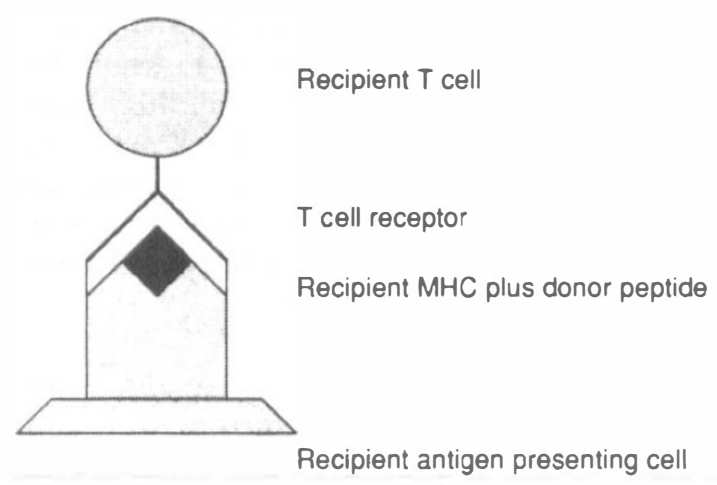

Fig. 3. Direct and indirect recognition of graft antigens by recipient $T$ lymphocytes. The receptors of $T$ cells within the graft recipient may react directly with the MHC antigens expressed on the transplanted tissue. This interaction, which is unique to the transplant situation, is referred to as route I or direct recognition of alloantigens and probably occurs because all peripheral $T$ cells have been positively selected in the thymus to bind to MHC molecules. Up to $10 \%$ of the peripheral T cells of one individual may react with the MHC alloantigens of another individual. The manner in which all other antigens (apart from MHC alloantigens) are recognised by T cells is as peptide fragments presented in the groove of the MHC molecules on antigen presenting cells $(A P C)$. In the case of transplanted tissues, proteins from the graft are processed and presented in the conventional way by recipient $T$ cells. This is known as route II or indirect recognition of alloantigen.

\section{LOG ANTIBODY TITRE}

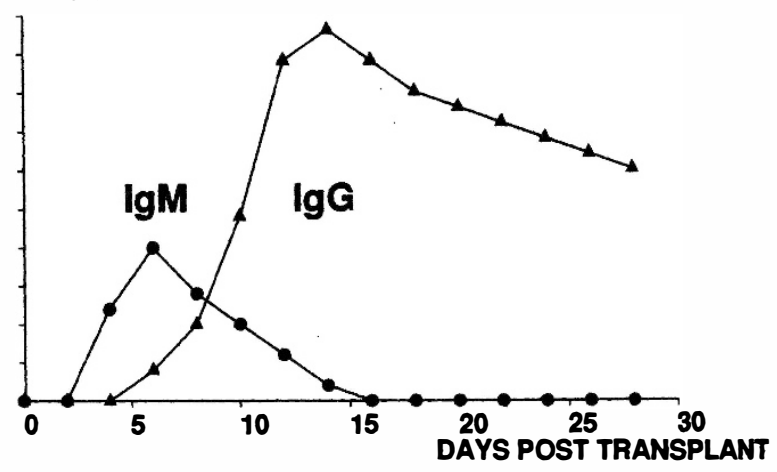

Fig. 5. The antibody response to allografts. The first antibody to appear in the serum after transplantation of skin or an organ allograft is IgM. This antibody is detected in the serum from day 3 or 4 and rapidly reaches peak levels by about day 7. The appearance of IgG follows and the maximal titre usually occurs by about day 14. 
dendritic cells, ${ }^{3} \mathrm{~T}$ helper cells of the recipient can be activated directly by the donor APC which present complexes of foreign donor MHC molecules and graft-derived peptides (Fig. 3). Alternatively, proteins shed from the graft are taken up by APC of the recipient so the $T$ helper cells are activated indirectly by recipient MHC class II molecules presenting graftderived peptides. ${ }^{4,5}$

The receptors for antigen on the surface of the B lymphocytes are the preformed specific antibodies that the B cell is programmed to make. When a graft is introduced only those clones of recipient B cells with receptors of the appropriate specificity to bind the donor antigen will be triggered to respond. Donor antigens shed from the graft are taken up by the process of receptor-mediated endocytosis and are concentrated within the B cell, where they are degraded to peptide fragments, incorporated into the groove of MHC class II molecules and arrayed on the surface of the B cell as MHC-peptide complexes. Thus, both the APC and the B cells are able to process and present antigen, and the MHC-peptide complexes which appear on the B cells are also to be found on the APC. In this way a T helper cell activated by the indirect antigen presenting pathway can then interact in a cognate, physical manner through $\mathrm{T}$ cell receptor/B cell MHC-peptide conjunction with the $\mathrm{B}$ cells able to make anti-donor antibody (Fig. 4).

The uptake of antigen by a B cell triggers certain metabolic changes which lead to the expression of adhesion molecules and receptors for cytokines, leaving the $\mathrm{B}$ cell in a state of partial activation. The $B$ cell-T helper cell contact allows the $T$ cell to signal the $\mathrm{B}$ cell to complete its round of activation by (1) providing cytokines such as IL-4 (B cell growth factor or BCGF), IL-5 (B cell differentiation factor I or BCDF 1) and IL-6 (BCDF II), and (2) direct surface-surface interaction of certain adhesion molecule pairs. These 'second signals' are necessary for B cells to develop into antibody-producing plasma cells or memory B cells.

$\mathrm{T}$ helper cell cytokines including IFN $\gamma$ also cause

Table I. Antibody effector mechanisms

Simple binding to antigen

Precipitation of soluble antigens

Agglutination of particulate antigens

Neutralisation of toxins

Neutralisation of infectivity

Activation or inhibition of cell functions

Complement fixation

Cell lysis

Thrombogenesis

Enhanced phagocytosis

Proinflammatory effects

Binding to Fc receptors

Enhanced phagocytosis

'Arming' of cells for ADCC

ADCC, Antibody-dependent cell-mediated cytotoxicity. activated B cells to switch from the synthesis of IgM antibodies to make $\operatorname{IgG}, \operatorname{IgE}$ and $\operatorname{IgA}$. This immunoglobulin class switch, involving the excision of genomic DNA, is irreversible. The general form of the response to an organ or skin allograft is an early IgM response detectable after 3 days and peaking within the first week, and an IgG response which is first detected at about day 5 or 6 after grafting and is maximal around day 14 (Fig. 5).

\section{THEORETICAL EFFECTS OF DONOR-RECIPIENT MHC MATCHING ON THE ANTIBODY RESPONSE TO GRAFTED TISSUES}

When the donor and recipient are mismatched for MHC class II antigens the T helper cells involved in the anti-graft antibody response are those which recognise antigen by the indirect route, i.e. recipient $\mathrm{T}$ cells respond to recipient MHC plus donor peptide. ${ }^{5}$ However, if the donor and recipient are matched for the MHC class II antigens, donor MHC plus donor peptide complexes are the same as those created by recipient MHC binding donor peptide. In these circumstances, recipient $\mathrm{T}$ cells directly activated by donor APC, the dendritic cells in the graft, can provide help for B cells elaborating antigraft antibodies. Consequently, at least in theory, matching the donor and recipient for HLA-DR antigens could paradoxically increase the $B$ cell response while the T-cell-mediated rejection response is reduced.

\section{ANTIBODY-MEDIATED GRAFT DAMAGE}

The mechanisms of antibody action can be classified as simple antigen binding, fixation of complement and binding to $\mathrm{Fc}$ receptors (Table I).

An antibody without an $\mathrm{Fc}$ region can still bind to

Table II. The role of antibodies in transplant rejection

\begin{tabular}{|c|c|}
\hline Type of transplant & Effects of antibody \\
\hline $\begin{array}{l}\text { Cell suspensions } \\
\text { (e.g. marrow and islets) }\end{array}$ & $\begin{array}{l}\text { Very vulnerable to lytic damage and } \\
\text { ADCC }\end{array}$ \\
\hline Skin grafts & $\begin{array}{l}\text { Generally regarded as resistant to } \\
\text { acute antibody-mediated damage }\end{array}$ \\
\hline \multirow[t]{3}{*}{ Organ grafts } & $\begin{array}{l}\text { Hyperacute rejection (in minutes or } \\
\text { hours) caused by the activation of the } \\
\text { classical complement cascade by pre- } \\
\text { formed anti-HLA, ABO and other } \\
\text { antibodies reactive with graft antigens }\end{array}$ \\
\hline & $\begin{array}{l}\text { Acute rejection (in days or weeks) } \\
\text { usually thought of as a cell-mediated } \\
\text { reaction, but antibody can cause } \\
\text { rejection with the same tempo and } \\
\text { may contribute to acute graft rejection }\end{array}$ \\
\hline & $\begin{array}{l}\text { Chronic rejection (in months or years) } \\
\text { may be a response to endothelial } \\
\text { activation and damage by antibodies } \\
\text { (or other causes) leading to fibrosis } \\
\text { and vascular intimal proliferation and } \\
\text { occlusion }\end{array}$ \\
\hline Corneal grafts & Not clear \\
\hline
\end{tabular}


Table III. Rejection of skin and corneal transplants in the Lewis to DA rat transplantation model

\begin{tabular}{lllrcl}
\hline Group & Graft 1 & Graft 2 & $n$ & $\begin{array}{c}\text { MST (days) } \\
\text { of graft 2 }\end{array}$ & $\begin{array}{c}\text { Statistical } \\
\text { significance }\end{array}$ \\
\hline 1 & None & Cornea & 16 & 14 & \\
2 & Skin & Cornea & 16 & 9 & $p<0.001$ \\
3 & None & Skin & 12 & 10 & \\
4 & Cornea & Skin & 10 & 10 & Not significant \\
5 & None & Skin & 16 & 10 & \\
6 & Skin & Skin & 14 & 8 & $p<0.001$ \\
\hline
\end{tabular}

DA rats were transplanted with Lewis rat skin or cornea (graft 1). After they had rejected their first graft they were given another graft (graft 2) as shown. In other experiments (data not shown) the specificity of sensitisation was demonstrated by using first grafts from third party, $\mathrm{AO}$ donor rats. $n$, number in each group; MST, median survival time of the second graft in days. Statistical significance was determined by the Mann-Whitney non-parametric $U$-test.

antigen and precipitate soluble antigens, agglutinate particulate antigens, neutralise toxins and virus infectivity and, upon binding to cell surfaces, can activate or interfere with cellular functions without killing the cell. Binding of intact antibody can trigger activation of the complement cascade leading to the lysis of cells, thrombogenesis, enhanced phagocytosis (opsonisation) and the release of proinflammatory complement fragments. Intact antibodies can be taken up by cells which have receptors for the Fc region of antibody molecules, leading to the 'arming' of these cells by providing them with acquired receptors. Such cells include those of the monocyte/ macrophage series as well as the large granular lymphocytes (LGL). Armed macrophages and LGL can act as killer cells in the process of antibodydependent cell-mediated cytotoxicity (or ADCC for short). Even low concentrations of antibody can arm cells effectively for ADCC.

\section{ANTIBODIES IN GRAFT REJECTION}

Different types of graft are known to differ in their susceptibility to antibody-mediated damage (Table II).

Suspensions of cells or tissues such as bone marrow or isolated pancreatic islets are very vulnerable to complement-mediated lysis and ADCC in vitro. By contrast, it is generally considered that antibody plays no role in the rejection of

Table V. The effect of treating corneal graft recipients with antiCD4 or anti-CD 8 monoclonal antibodies

\begin{tabular}{llrcl}
\hline Group & Treatment & $n$ & MST (days) & Significance \\
\hline 1 & None & 16 & $14.2 \pm 1.3$ & \\
2 & Anti-CD4 antibody & 6 & $24.7 \pm 6.8$ & $p<0.001$ \\
3 & Anti-CD8 antibody & 3 & $14.7 \pm 4.7$ & Not significant \\
\hline
\end{tabular}

DA rats were treated with monoclonal antibodies to deplete circulating CD4 and CD8 cells before grafting of corneas from Lewis rats.

$n$, number in the group; MST, mean survival time \pm standard deviation.

Statistical significance was determined using Student's $t$-test.
Table IV. The effect of graft bed prevascularisation on corneal allograft rejection in the Lewis to DA rat model

\begin{tabular}{llccc}
\hline Group & Graft bed & $n$ & MST (days) & Significance \\
\hline 1 & Normal, avascular & 3 & 12 & \\
2 & Prevascularised & 8 & 8 & $p=0.012$ \\
\hline
\end{tabular}

Corneal allografts from Lewis rats were transplanted to normal DA recipients or to rats in which vascularisation of the graft bed had been induced by the placement of a silk suture.

$n$, number in the group; MST, median survival time of the graft. Statistical significance was determined using the Mann-Whitney non-parametric $U$-test.

skin allografts, although there are some welldocumented situations where this does occur. ${ }^{6,7}$ The effects of antibody on organ grafts have been most widely examined, but there is still debate about their importance and specificity.

Hyperacute rejection is clearly due to preformed anti-donor antibodies in the recipient causing complement fixation in the graft, rapid thrombogenesis and the demise of the transplanted organ within minutes or hours. The damaging antibodies may be 'natural', such as those of the ABO system, or may have been induced, including anti-HLA antibodies induced by rejection of a previous graft, blood transfusions or multiparity. The 'cross-match test' for preformed anti-donor antibodies has largely eliminated the clinical problem of hyperacute rejection. In the developing arena of xenotransplantation one major barrier to success is the presence of natural antibodies in humans against protein and carbohydrate antigens of animal tissues and the immediate damage that they inflict. Much work is going on to reduce complement levels, to remove these natural antibodies, and to manipulate donor animals genetically either to not express certain target antigens or to be more resistant to complement-mediated damage.

Acute rejection is largely a T-cell-mediated process, although a role for antibodies cannot be ruled out. Indeed, antibody can cause acute organ allograft rejection in experimental models. ${ }^{8}$ In clinical practice, declining graft function in the absence of histological evidence of a cellular infiltrate in the graft attracts the diagnosis by default of 'humoral rejection', and in such cases graft function improves after plasmapheresis to remove

Table VI. The antibody response of DA recipients to Lewis corneal allografts

\begin{tabular}{lcc}
\hline & \multicolumn{2}{c}{ Maximal antibody response } \\
\cline { 2 - 3 } Graft & Days after graft & Titre \\
\hline Skin & $10-14$ & $1 / 2048$ \\
Cornea & $21-28$ & $1 / 128$
\end{tabular}

Serial serum samples from DA rats grafted with skin or corneas from Lewis rats were tested for the presence of lymphocytoxic anti-donor antibodies. The table shows the day when the antibody response was highest and the maximum titre achieved. 
antibodies. Antibodies to HLA antigens and to endothelial and parenchymal cells have been implicated.

Chronic rejection appears to be a response to endothelial cytomegalovirus cell activation or damage. The causes may be various, including a low-grade cellular reaction or cytomegalovirus infection. One putative mechanism is that anti-endothelial cell antibodies activate the endothelium, leading to the release of the growth factors (TGF $\beta$, PDGF, IGF, EGF) involved in tissue repair. The outcome is fibrosis and a concentric vascular intimal proliferation resulting in occlusion of the vessels of the graft. ${ }^{9}$

\section{ANTIBODIES IN CORNEAL GRAFT REJECTION}

Anti-corneal antibodies have been detected after both clinical ${ }^{10,11}$ and experimental ${ }^{12,13}$ grafting and, in one clinical case, antibody was apparently the sole mediator of rejection. ${ }^{14}$ However, systemic humoral immunity is detected only in some patients, ${ }^{15,16}$ and in some experimental models no antibody was found. It is not certain whether the antibodies that are formed and are detectable in the serum penetrate the transplanted cornea and, if they do, whether they are responsible for graft damage.

In our laboratory we have studied the acute rejection of rat corneas in the Lewis to DA strain combination (across both major and minor histocompatibility barriers). Some of this work has been published. ${ }^{17-19}$ In this model corneas are rejected in 14 days (Table III, group 1), significantly more slowly than skin grafts (group 5). Skin and cornea share antigens, since sensitisation of recipients with previous skin transplants accelerates the rejection of corneal grafts (group 2). However, rejection of a cornea does not sensitise for accelerated skin graft rejection (group 4). Hence, the cornea is antigenic but is evidently less immunogenic than skin, although this may not necessarily be a property of the tissue itself because corneas transplanted to a prevascularised graft bed suffer more rapid rejection (Table IV). The mechanism of rejection has been studied in this model. As expected, treatment of recipient with anti-CD4 monoclonal antibody delays corneal graft rejection ${ }^{17}$ while treatment with anti-CD8 monoclonal antibody does not (Table V).

The result of treating with anti-CD4 antibody emphasises the pivotal role of the $\mathrm{T}$ helper cell in rejection (see Fig. 1) but does not distinguish the mechanism(s) involved. The lack of effect using antiCD8 antibody treatment suggests that cytotoxic $\mathrm{T}$ lymphocytes (CTL) are not of major importance. This conclusion is compatible with our observation of the absence of CTL in the spleen or lymph nodes of rats rejecting corneal grafts, in contrast to those rejecting skin. The anti-CD8 antibody result also implies that ADCC is not a major mechanism of graft damage either since the effector cells, LGL, in the rat bear the CD 8 marker.

The DA rat does make antibodies to donor antigens after corneal grafting, detected in the serum as lymphocytotoxic activity in the presence of complement (Table VI).

The maximal antibody response to a skin graft occurs about day 12 after transplantation and reaches a titre in excess of $1 / 2000$. By comparison the antibody response to a corneal graft is slower and lower, peaking at 3-4 weeks and having a maximum titre of about 1/100. At the time of corneal graft rejection no antibody could be detected, and the response peaked 6-8 days after corneal graft rejection.

In summary, then, of the three effector arms of rejection, namely CTL, antibody and inflammation, there is no evidence for CTL activation, the antibody response is too low and too late to account for rejection and ADCC is probably excluded as a major mechanism. Thus, an inflammatory reaction is the most likely cause of corneal rejection in our model and, indeed, we have published evidence showing the presence of $\mathrm{CD}^{+} \mathrm{T}$ cells and macrophages in rejecting corneas, ${ }^{17,18}$ - although we still cannot exclude a role for low levels of antibody or for the proinflammatory products of complement activation.

\section{CONCLUSIONS}

Antibodies do contribute to graft damage in many situations, but direct evidence for their role in the demise of corneal grafts is scant. In our model of acute corneal allograft rejection the transplant is rejected before the antibody response becomes evident. Perhaps antibodies have a function in chronic rejection of corneal allografts by binding to endothelial cells without killing them, a possibility that deserves further investigation.

Key words: Antibody, Clinical, Corneas, Experimental, Rejection, Transplantation.

\section{REFERENCES}

1. Hutchinson IV. Transplantation and rejection. In: Roitt I, Brostoff J, Male D, editors. Immunology. London: Mosby Year Book, 1993:23.1-23.14.

2. Hutchinson IV. Effector mechanisms in transplant rejection: an overview. In: Rose ML, Yacoub $\mathrm{MH}$, editors. Immunology of heart and lung rejection. London: Edward Arnold, 1993:3-21.

3. Hutchinson IV. Cellular mechanisms of allograft rejection. Curr Opin Immunol 1991;3:722-8.

4. Lechler RI, Batchelor JR. Restoration of immunogenicity to passenger cell-depleted kidney allografts by the addition of donor strain dendritic cells. J Exp Med 1982;155:31-41.

5. Hutchinson IV. The immune response to transplanted tissues: recognition and regulation. J Pathol 1994; 173S:238.

6. Berden JHM, Gerlag PGG, Hagemann FFHM, Koene 
RAP. Role of antiserum and complement in the acute antibody-mediated rejection of mouse skin allografts in strain combinations with increasing histoincompatibility. Transplantation 1977;24:175-82.

7. Berden JHM, Capel PJA, Koene RAP. The role of complement factors in acute antibody-mediated rejection of mouse skin allografts. Eur $J$ Immunol 1978;8:158-62.

8. Morton AL, Bell EB, Bolton EM, Marshall HE, Roadknight C, McDonagh M, Bradley JA. CD4 ${ }^{+}$T cell-mediated rejection of major histocompatibility complex class I-disparate grafts: a role for alloantibody. Eur J Immunol 1993;23:2078-84.

9. Hayry $\mathrm{P}$, Isoniemi $\mathrm{H}$, Yilmaz $\mathrm{S}$, Mennander $\mathrm{A}$, Lemstrom K, Raianen-Sokolowski A, et al. Chronic allograft rejection. Immunol Rev 1993;134:33-81.

10. Jager MJ, Volker Dieben HJ, Vos A, et al. Cellular and humoral anticorneal responses in corneal transplantation. Arch Ophthalmol 1991;109:972-7.

11. Gunnett N, Kristensen T, Kissmeyer-Nielson F, Ehlers $\mathrm{N}$. Occurrence of lymphocytotoxic lymphocytes and antibodies after corneal transplantation. Acta Ophthalmol (Copenh) 1976;54:167-73.

12. Treseler PA, Sanfilippo F. Humoral immunity to heterotopic corneal allografts in the rat. Transplantation 1985;39:193-6.
13. Gebhardt BM.The role of class II antigen expressing cells in corneal allograft immunity. Invest Ophthalmol Vis Sci 1990;31:2254-60.

14. Ehlers N, Olsen T, Johnsen $\cdot H E$. Corneal graft rejection probably mediated by antibodies. Acta Ophthalmol (Copenh) 1981;59:119-25.

15. Nelken E, Michaelson IC, Nelken D, Gurcevitch J. Studies on antigens in the human cornea and their relationship to corneal grafting in man. J Lab Clin Med 1957;49:745-52.

16. Stark WJ, Opelz G, Newsome D, Brown R, Yankee R, Terasaki PI. Sensitisation to human lymphocyte antigens by corneal transplantation. Invest Ophthalmol Vis Sci 1978;12:639-45.

17. Brown R, Ayliffe W, Alam Y, McLeod D, Hutchinson IV. The effect of predsol on cells infiltrating rat corneal allografts. Invest Ophthalmol Vis Sci 1991; 32(Suppl):2209.

18. Ayliffe W, Alam Y, Bell EB, McLeod D, Hutchinson IV. Prolongation of rat corneal graft survival by treatment with anti-CD4 monoclonal antibody. Br J Ophthalmol 1992;76:602-6.

19. Ayliffe W, McLeod D, Hutchinson IV. The effect of blood transfusions on rat corneal graft survival. Invest Ophthalmol Vis Sci 1992;33:1974-8. 